\title{
Unexpected stressful experiences in transition from medical student to junior doctor in Ardabil medical sciences university centers and affiliated hospitals 2005
}

\author{
Zahra Tazakori*1, Zahra Hashempour ${ }^{2}$, Parviz Molavi ${ }^{3}$ and \\ Mansoureh Karimollahi ${ }^{1}$
}

Address: ${ }^{1}$ Nursing and midwifery, Ardabil Medical Sciences University, Ardabil, Iran, ${ }^{2}$ Ardabil Medical Sciences University, Ardabil, Iran and ${ }^{3}$ Dr Fatem Hospital, Ardabil Medical Sciences University, Ardabil, Iran

* Corresponding author

\author{
from International Society on Brain and Behaviour: 3rd International Congress on Brain and Behaviour \\ Thessaloniki, Greece. 28 November - 2 December 2007 \\ Published: 17 April 2008 \\ Annals of General Psychiatry 2008, 7(Suppl I):S309 doi:I0.I 186/I744-859X-7-SI-S309
}

This abstract is available from: http://www.annals-general-psychiatry.com/content/7/SI/S309

(c) 2008 Tazakori et al.; licensee BioMed Central Ltd.

\section{Background}

The transition from medical student to junior doctor is difficult for many reasons. These include the content of the undergraduate curriculum (which often covers numerous subjects which have little or no application to clinical practice), the lack of an apprenticeship period with close supervision, and the extraordinary nature of the first year junior doctor's job in terms of clinical responsibilities, horrendous workload, and resulting personal and professional unexpected stress.

\section{Materials and methods}

This survey was a descriptive study in which, stressful experiences of new graduate junior doctor during transition period has been assessed. The sample consisted of 150 new graduates working in teaching centers and affiliated hospitals of Ardabil Medical Sciences University which during research conduction placed at the end of first six month of work. The data were collected using a questionnaire in 5 parts: the first part is related to demographic characteristics and other parts were including individual, managerial, supportive and treatment stressful experiences. Data analyzed using descriptive and analytic statistic with spss software.

\section{Results}

The finding of this study indicated that many of new graduates had high level of individual and treatment stressful experiences. Most of junior doctors believed that they had not enough knowledge for treating their patients, they were not able diagnoses and distinguish problem of their patients and also thy believed that most of people did not trust them, not implementation of orientation programs at begin of job and individual stressful experiences were other problems.

\section{Conclusions}

It is important that medical universities plan some programs for medical students of final year to recognizing the difficulties that they are likely to face as junior doctors and the ways in which they might overcome them. 